\title{
Multi-objective Comprehensive Optimal Management of Construction Projects Based on Particle Algorithm
}

\author{
Zijing Wang \\ Luoyang Institute of Science and Technology, Luoyang, Henan 471023, China \\ E-mail: wzjzijing@yeah.net
}

Keywords: construction project management, particle swarm optimization, multi-objective optimization, genetic operator

Received: July 25, 2019

\begin{abstract}
Construction industry is one of the pillars of rapid economic development. The optimization of construction project management can greatly optimize the cycle, cost and quality of projects. In this paper, the multi-objective management optimization model of construction projects and the particle swarm optimization (PSO) algorithm for calculating the optimal solution of the model are briefly introduced, genetic operators are introduced into the PSO algorithm to prevent premature phenomenon, so as to improve the accuracy of the solution, and then case analysis is performed on a single-storey building project. The results show that the algorithm converges to stability and obtains the optimum solution set after 400 times of iterations and a total of 63250 seconds. The construction period of each process of the solution with the shortest total construction period in the optimum solution set is shorter than that before optimization, the total construction period reduces by 56 days, the total cost reduces by 520,000 yuan, and the total quality increases by 3.58. In summary, the improved PSO algorithm can effectively optimize the management of construction projects.
\end{abstract}

Povzetek: Predstavljen je izboljšani algoritem na osnovi delcev in večkriterijske optimizacije za izboljšanje vodenja gradbeniških projektov.

\section{Introduction}

Construction industry plays an indelible role in the rapid economic development [1]. In the construction process, whether building materials or labor force are disposable, different types of construction projects have different plans, and plans are also disposable. There is basically no case of modifying the plan after half of the construction according to the plan, so it needs to perform reasonable optimization allocation on the projects in the construction planning [2]. The main objectives of management optimization of construction projects are construction period, cost and quality, and the relevance between the optimization objectives is high. Finally, the problem of construction management optimization is transformed into a problem of multi-objective optimization, and the balance is obtained from the multi-objective to achieve the optimization effect of short construction period, low cost and high quality as far as possible [3].

\section{Related works of engineering projects}

Elbeltagi et al. [4] developed a multi-objective overall optimization model for project scheduling by using the new evolutionary strategy of particle swarm optimization and compromise solution based on Pareto optimal boundary. The experimental results showed that the model will help construction managers and decision makers to complete projects on time and reduce budgets through using existing information and resources. Senouci et al. [5] proposed a multi-objective optimization model for the problem of construction project scheduling under extreme weather conditions. The case analysis results showed that extreme weather had an impact on the construction period and cost, and the optimization model could minimize the time and cost of construction projects in extreme weather areas. Cheng et al. [6] proposed a multi-objective differential evolution algorithm based on objection to solve the problem of the time cost utilization and work-shift trade-off of the end of construction projects. The case analysis results verified the effectiveness of the algorithm.

In this paper, the multi-objective management optimization model of construction projects and the particle swarm optimization (PSO) algorithm for calculating the optimal solution of the model are briefly introduced, genetic operators are introduced into the PSO algorithm to prevent "premature", so as to improve the accuracy of the solution, and then case analysis is performed on a single-story building project. 


\section{Multi-objective management optimization model for construction projects}

The multi-objective management of construction projects includes three objectives, namely, construction period, quality and cost respectively. The construction period represents the time required to complete the construction project, the quality represents the quality of the completed construction project, and the cost represents the cost required to complete the construction project. In the construction project management, the network plan chart is usually used to plan the construction period. In this study, the double code network chart [7] is used to represent the construction period plan of the construction project, the nodes in the double code network represent events, and the line arrows between nodes represent the working process. In actual construction projects, the network plan can not only have one line, which must have several branches, meaning that part of the construction process can be carried out simultaneously and finally converge at the end node. Therefore, the construction period in a construction project is determined by the key path which takes the longest time. The calculation formula of the construction period [8] is:

$$
T=\sum_{i \in N} T_{i}
$$

where $T$ represents the total construction period of the construction project, $T_{i}$ represents the time consumed in the i-th working process, and $N$ represents the set of work in the key path.

For a construction project, the cost of its investment will greatly affect the schedule of the project, in other words, the length of the construction period can determine the cost of the investment. On the whole, the cost is negatively correlated with the construction period, and the relationship [9] is:

$$
C=\sum_{i=1}^{n}\left[C_{i n}+\partial_{i}\left(t_{i}-t_{i n}\right)^{2}\right]+\beta T_{C}+\gamma\left(T_{P}-T_{C}\right),
$$

where $C$ represents the total cost, ${ }^{C}$ in represents the direct cost of the $\mathrm{i}$-th job in the expected working time, ${ }^{\partial_{i}}$ represents the cost increment parameter of the ith job, ${ }^{t_{i}}$ represents the actual working time of the i-th job, ${ }^{t_{i n}}$ represents the estimated time of the i-th job, $\beta$ represents the indirect cost parameter, ${ }^{T_{C}}$ represents the actual total working time, $\gamma$ represents the penalty coefficient, and $T_{P}$ represents the estimated total working time.

Compared with the construction period and cost in the construction project, the quality of the construction is relatively difficult to quantify, and the relationship between the quality and the construction period of the construction is not a single positive (negative) correlation.

In this study, the quality level index is used to evaluate the quality of each process in the project, and then the relationship between the construction period and the quality is established based on the reliability theory [10]:

$$
\left\{\begin{array}{l}
Q=\left[1-\prod_{j=1}^{n}\left(1-q_{j}^{i n}\right)\right] \cdot q_{i} \\
q_{i}=\ln \left(\frac{\left(e-e^{q_{i l}}\right) t_{i}}{t_{i l}-t_{i s}}+\frac{e^{q_{i l}} t_{i l}-e t_{i s}}{t_{i l}-t_{i s}}\right)
\end{array},\right.
$$

where $Q$ represents the total quality of construction projects, ${ }^{q_{i}}$ represents the quality level index of the i-th job, ${ }^{i n}$ represents the quality level index of the j-th job before the i-th job, $q_{i l}$ represents the estimated quality level index of the $\mathrm{i}$-th job, and $t_{i l}, t_{i s}$ represent the longest and shortest working time for the $\mathrm{i}$-th job respectively.

In the process of construction, construction companies always hope to complete construction projects faster, better and cheaper, but in fact, the construction period, cost and quality are mutually restricted by each other, i.e, the improvement of the quality will increase the cost and construction period, and the reduction of construction period will reduce the quality and increase the cost [11]. Therefore, the problem of management optimization of construction projects is a problem of multi-objective optimization, and the obtained final solution is the overall optimal solution of the three objectives compromising with each other instead of the optimal solution of one of them. Combining with the above, the multi-objective management optimization model of construction projects is:

Objective function:

$$
\left\{\begin{array}{l}
\min T=\sum_{i \in N} T_{i} \\
\min C=\sum_{i=1}^{n}\left[C_{i n}+\partial_{i}\left(t_{i}-t_{i n}\right)^{2}\right]+\beta T_{C}+\gamma\left(T_{P}-T_{C}\right) \\
\max Q=\left[1-\prod_{j=1}^{n}\left(1-q_{j}^{i n}\right)\right] \cdot q_{i}
\end{array},\right.
$$

Conditions:

$$
\left\{\begin{array}{l}
t_{i s} \leq t_{i} \leq t_{i l} \\
c_{i s} \leq c_{i} \leq c_{i l} \\
q_{i s} \leq q_{i} \leq 1
\end{array}\right.
$$

where $c_{i s}, c_{i}, c_{i l}$ represent the minimum cost, actual cost and maximum cost of the i-th job respectively, and $q_{i s}, q_{i}$ represent the worst quality and actual quality of the i-th job. 


\section{The improved PSO algorithm}

PSO algorithm [12] is also called "bird swarm foraging algorithm" as it is obtained by studying the foraging and migration behavior of birds. Its principle is to obtain the global optimal solution by tracing the current optimal solution. In the process of operation, the search direction of the optimal solution is determined by the value of fitness, the fitness is used to judge the quality of the solution, and the global optimal solution is found out by comparing the self-optimal solution with the current optimal solution.

Through the iteration formula, the position and velocity of particles are updated continuously to find out the individual optimal solution and the overall optimal solution. The iteration formula [13] is:

$$
\left\{\begin{array}{l}
V_{i+1}=V_{i}+a_{1} \cdot x_{1} \cdot\left(\text { pbest }_{i}-P_{i}\right)+a_{2} \cdot x_{2} \cdot\left(\text { gbest }_{i}-P_{i}\right) \\
P_{i+1}=P_{i}+V_{i}
\end{array},\right.
$$

where $P_{i}, V_{i}$ represent the position and velocity of

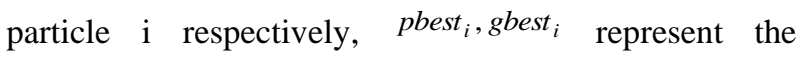
individual optimal position and global optimal position respectively, $a_{1}, a_{2}$ represent learning factors, and $x_{1}, x_{2}$ represent random numbers, which are evenly distributed between 0 and 1 . When the optimal solution is searched or the preset maximum number of iterations is reached, the iteration stops.

The basic principle of general PSO algorithm, as mentioned above, is relatively simple in implementation, but it is easy to converge to the local optimal solution prematurely in the process of searching for the optimal solution. In order to improve the performance of the PSO algorithm and make up for its shortcoming of "premature", in this study, crossover and mutation operators [14] in genetic algorithm are introduced to form an improved PSO algorithm.

The operation flow of the PSO algorithm improved by genetic algorithm is shown in Figure 1, and the steps are as follows:

(1) The related parameters are input, including the size of particle swarm, the crossover and mutation probability, learning factors and the maximum times of iterations. The size of particle swarm is generally between 50 and 100, the probabilities of crossover and mutation are generally between 0.5 and 1 , and then particles are randomly generated. The dimension of particles is determined by the number of working processes of the whole construction project, and a particle represents a set of time consuming of all processes of a construction project. After the particles are generated, the position and velocity of the particles are randomly initialized.

(2) The value of fitness of the particle is calculated, and the individual and global optimal solution are selected from the particle swarm. In this study, the objective function above is used as the fitness function.

$$
\min F(X)=\left\{\begin{array}{l}
\min T(X) \\
\min C(X) \\
-\max Q(X)
\end{array},\right.
$$

where $F(X)$ represents the value of fitness, the final goal is to converge it to the minimum, and $X$ represents particle swarm. At the same time, due to the difference of the units between the construction period, cost and quality in the objective function, the accuracy will be affected when evaluating, so it needs to standardize the value of fitness [15]. The equation is:

$$
y=\frac{x-\bar{x}}{s},
$$

where $x$ represents the value of fitness that needs standardization, $y$ represents the value of fitness after standardization, $\bar{x}$ represents the average of the fitness values of all particle, and $s$ represents the variance of the fitness values of all particle.

(3) The individual and global optimum solutions are selected by the values of fitness, and equation (6) is used to update the velocity and position of particle swarm. Then the algorithm is judged whether the termination conditions is met, including that the fitness function converges to stability and the maximum number of times of iterations is reached. If the termination condition is met, the results will be output directly; otherwise the next genetic operation for the particle swarm will be carried out.

(4) Genetic operation, i.e., in this study, the phenomenon of "premature" of the traditional PSO algorithm is overcome by introducing crossover and mutation operations of genetic algorithm [16]. In the crossover operation in this paper, a random number between 0 and 1 is generated in each dimension of the particles. When the random number is less than the crossover probability, the parameters in the dimension of the particle will be exchanged with those in the same dimension of another particle to obtain a new individual particle. In the mutation operation, a random number between 0 and 1 is also generated in each dimension of

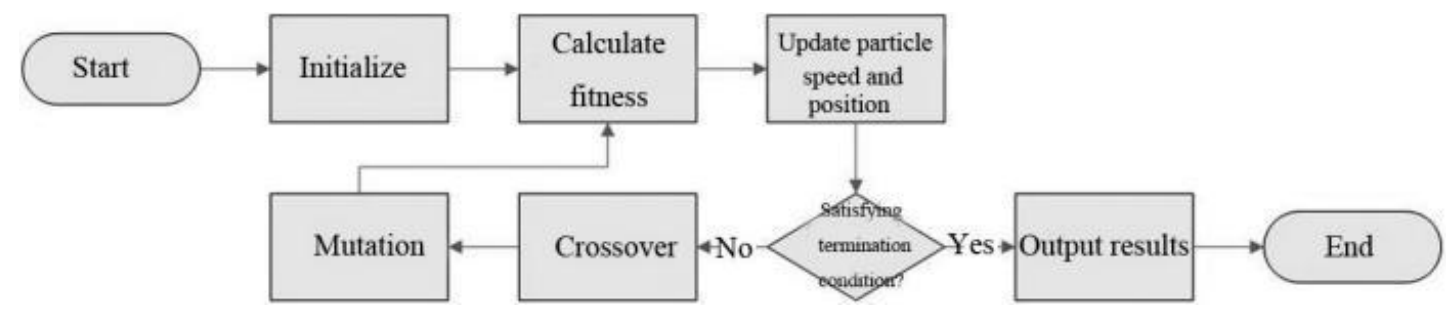

Figure 1: The operation flow of the improved PSO algorithm. 


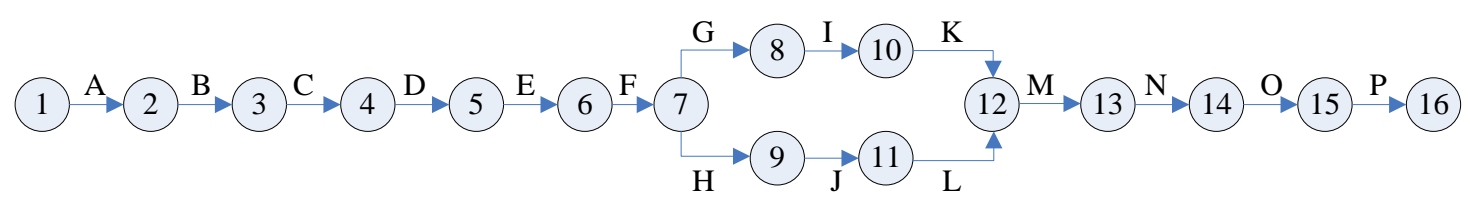

Figure 2: The plan of the double code network.

the particles. When the random number is less than the mutation probability, the parameters in the dimension of the particle change randomly in a limited range to obtain a new individual.

The steps (2), (3) and (4) are repeated until the algorithm reaches the termination condition, and the calculation results are output.

\section{Case analysis}

\subsection{Case overview}

XX Construction Company undertook a single-storey construction project, the cost provided in the contract was 2.8 million yuan, and the construction period was limited to 250 days. At the same time, in order to determine the quality of the building, the company invited 10 experts to evaluate the requirements of the contract and the quality of the project that the company can complete. The highest is 1 , the lowest is 0 , the lowest qualified index of the quality of single work is 0.6 , and finally the average value is taken. There are 16 working procedures in the construction project, and the plan of double code network is in Figure 2.

\subsection{Parameter setting}

According to the plan of the double code network in Figure 2, there are 16 processes in the construction project, and the related parameters of each process are in Table 1. The related parameters of PSO algorithm are as follows: the size of the population is 50 , the dimension of the particle is 16 , the learning factors, are both set as 1.5 , the maximum number of times of iterations is 400 , and the probabilities of crossover and mutation in genetic operation are both 0.5 .

\begin{tabular}{|c|c|c|c|c|c|c|c|}
\hline $\begin{array}{c}\text { Work } \\
\text { serial } \\
\text { number }\end{array}$ & Work name & $t_{i s} /$ day & $t_{i l} /$ day & $\begin{array}{c}c_{i s} / \text { ten } \\
\text { thousand } \\
\text { yuan }\end{array}$ & $\begin{array}{c}c_{i l} / \text { ten } \\
\text { thousand } \\
\text { yuan }\end{array}$ & $q_{i s}$ & $q_{i l}$ \\
\hline A & $\begin{array}{l}\text { Construction } \\
\text { preparation }\end{array}$ & 2 & 4 & 4 & 5 & 0.67 & 0.87 \\
\hline $\mathrm{B}$ & $\begin{array}{l}\text { Foundation } \\
\text { excavation }\end{array}$ & 8 & 10 & 6 & 10 & 0.65 & 0.89 \\
\hline $\mathrm{C}$ & Scaffolding & 15 & 20 & 6 & 11 & 0.66 & 0.91 \\
\hline $\mathrm{D}$ & Column & 7 & 11 & 11 & 16 & 0.69 & 0.91 \\
\hline $\mathrm{E}$ & Masonry & 6 & 8 & 7 & 10 & 0.66 & 0.89 \\
\hline $\mathrm{F}$ & Roof panel & 9 & 12 & 15 & 20 & 0.68 & 0.90 \\
\hline $\mathrm{G}$ & Roofing works & 15 & 20 & 25 & 30 & 0.66 & 0.87 \\
\hline $\mathrm{H}$ & Polished exterior wall & 30 & 40 & 36 & 50 & 0.68 & 0.91 \\
\hline I & $\begin{array}{l}\text { Doors and windows } \\
\text { construction }\end{array}$ & 7 & 10 & 10 & 15 & 0.66 & 0.89 \\
\hline $\mathrm{J}$ & Interior decoration & 25 & 30 & 15 & 20 & 0.66 & 0.89 \\
\hline $\mathrm{K}$ & $\begin{array}{l}\text { Door and window } \\
\text { paint }\end{array}$ & 30 & 40 & 30 & 40 & 0.66 & 0.89 \\
\hline $\mathrm{L}$ & $\begin{array}{l}\text { Piecemeal } \\
\text { Engineering }\end{array}$ & 8 & 12 & 10 & 15 & 0.67 & 0.90 \\
\hline $\mathrm{M}$ & Backfill & 3 & 5 & 3 & 5 & 0.66 & 0.89 \\
\hline $\mathrm{N}$ & $\begin{array}{l}\text { Hydropower } \\
\text { installation }\end{array}$ & 15 & 20 & 15 & 20 & 0.66 & 0.89 \\
\hline $\mathrm{O}$ & Operation detection & 3 & 5 & 3 & 5 & 0.69 & 0.91 \\
\hline $\mathrm{P}$ & $\begin{array}{l}\text { Check before } \\
\text { acceptance }\end{array}$ & 1 & 2 & 1 & 3 & 0.66 & 0.89 \\
\hline
\end{tabular}

Table 1: Relevant parameters of single-storey construction projects. 


\subsection{Optimization results}

After 400 times of iterations of the improved PSO algorithm, the value of fitness of the objective function converges to stability, the set of optimal solution is obtained, and the total time consumed for optimization calculation is $63250 \mathrm{~s}$. The first 25 sets of solutions in the set of optimal solution after the convergence of the fitness values are plotted with three objective functions as coordinate axes. Figure 3 shows that the $\mathrm{x}$-axis is the objective function of the construction period, the $y$-axis is the objective function of the cost, and the z-axis is the objective function of the quality. There is no unique solution as the problem of management optimization of construction project is a problem of multi-objective optimization. Each blue point in Figure 3 represents a type of arrangement combination of project work, and the curved surface formed by blue points is the set of optimal solution.

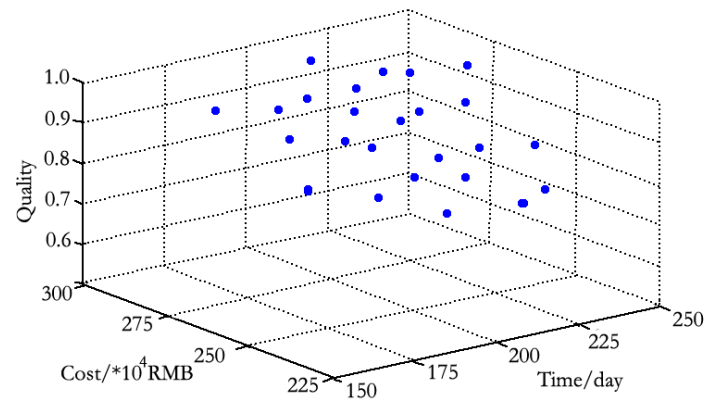

Figure 3: The scatter plot of the optimal solution of the improved PSO algorithm after optimization.

The optimal construction period combination of construction projects is obtained by the improved PSO algorithm, that is, there are 25 groups of solutions in the optimal solution set. Due to the space limitation, it is impossible to list all the optimized schemes obtained by calculation. However, any solution in the solution set can be used as the optimal solution and are just selected according to the actual needs. Therefore, in this paper, one group of solutions is chose based on the shortest total construction period as the standard, and the comparison

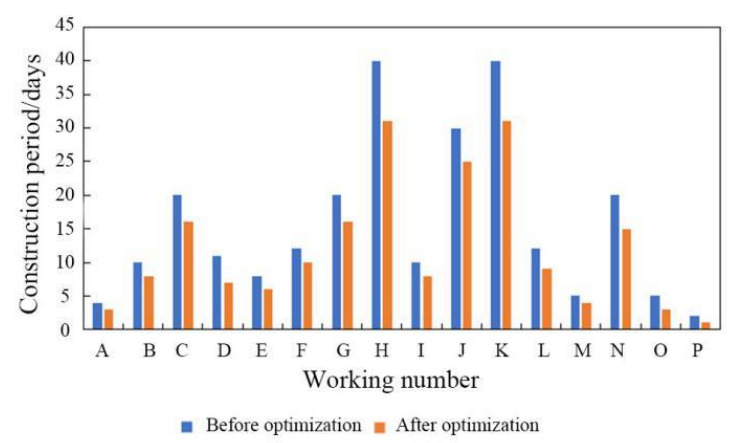

Figure 4: The construction period of each process of the improved PSO algorithm before and after optimization. between the construction period of each process and the construction period before optimization in the project is in Figure 4. It can be seen from Figure 4 that the construction period of each process after optimization is less than that before optimization, and the construction project after optimization management can reduce the construction period.

The optimization management of construction projects is a problem of multi-objective optimization, and the three optimization objectives, the construction period, cost and quality, interact with each other. Therefore, the total construction period, cost and quality of the construction project before and after optimization are compared. Table 2 shows that the total construction period of the construction project before optimization is 249 days, the total cost is 2.75 million yuan, and the total quality level index is 10.67 . After optimization, the total construction period is 193 days, the total cost is 2.23 million yuan, and the total quality level index is 14.25 . It can be seen that the optimized construction project not only reduces the construction period of 56 days, but also reduces the cost of 520,000 yuan, and improves the quality level of 358 .

\begin{tabular}{|l|c|c|}
\hline & $\begin{array}{c}\text { Before } \\
\text { optimization }\end{array}$ & $\begin{array}{c}\text { After } \\
\text { optimization }\end{array}$ \\
\hline $\begin{array}{l}\text { Total } \\
\text { construction } \\
\text { period/day }\end{array}$ & 249 & 193 \\
\hline $\begin{array}{l}\text { Total cost } \\
/ 10,000 \text { yuan }\end{array}$ & 275 & 223 \\
\hline $\begin{array}{l}\text { Total quality } \\
\text { level }\end{array}$ & 10.67 & 14.25 \\
\hline
\end{tabular}

Table 2: Total construction period, cost and quality before and after optimization.

\section{Conclusion}

In this paper, the multi-objective management optimization model of construction projects and the particle swarm optimization (PSO) algorithm for calculating the optimal solution of the model are briefly introduced, genetic operators are introduced into the PSO algorithm to prevent "premature", so as to improve the accuracy of the solution, and then case analysis is performed on a single-storey building project. The results are as follows.

(1) After 400 times of iterations, the algorithm converges to stability taking a total time consumption of $63250 \mathrm{~s}$, and the optimal solution set is obtained.

(2) The solution with the shortest total construction period is chose. Compared with the construction period of each process, total construction period, total cost and total quality of the construction project before optimization, the construction period of each process after optimization is obviously reduced, the total construction period after optimization is 193 days with 
the reduction of 56 days, the total cost is 2.23 million yuan with the reduction of 520,000 yuan, and the total quality is 1425 with the improvement of 358 .

\section{References}

[1] Prayogo D, Cheng MY, Wong FT, Tjandra D, Tran HD. (2018). Optimization model for construction project resource leveling using a novel modified symbiotic organisms search. Asian Journal of Civil Engineering, 19 (2), pp. 1-14. https://doi.org/10.1007/s42107-018-0048-x.

[2] Shahriari MR. (2016). Multi-objective optimization of discrete time-cost Tradeoff Problem in project networks using non-dominated sorting genetic algorithm. Journal of Industrial Engineering International, 12 (2), pp. 159-169. https://doi.org/10.1007/s40092-016-0148-8.

[3] Mavrotas G, Figueira JR, Siskos E. (2015). Robustness analysis methodology for multiobjective combinatorial optimization problems and application to project selection. Omega, 52 (Complete), pp. 142-155.

https://doi.org/10.1016/j.omega.2014.11.005.

[4] Elbeltagi E, Ammar M, Sanad H, Kassab M. (2016). Overall multiobjective optimization of construction projects scheduling using particle swarm. Engineering, Construction and Architectural Management, 23 (3), pp. 265-282. https://doi.org/10.1108/ECAM-11-2014-0135.

[5] Senouci AB, Mubarak SA. (2016). Multiobjective optimization model for scheduling of construction projects under extreme weather. Journal of Civil Engineering and Management, 22 (3), pp. 373-381. https://doi.org/10.3846/13923730.2014.897968.

[6] Cheng MY, Tran DH. (2015). Opposition-based Multiple Objective Differential Evolution (OMODE) for optimizing work shift schedules. Automation in Construction, 55, pp. 1-14. https://doi.org/10.1016/j.autcon.2015.03.021.

[7] Elbeltagi E, Ammar M, Sanad H, et al. (2016). Overall multiobjective optimization of construction projects scheduling using particle swarm. Engineering Construction \& Architectural Management, 23 (3), pp. 265-282. https://doi.org/10.1108/ECAM-11-2014-0135.

[8] Shahsavar A, Najafi A, Niaki STA. (2015). Three self-adaptive multi-objective evolutionary algorithms for a triple-objective project scheduling problem. Computers \& Industrial Engineering, 87, pp. 4-15. https://doi.org/10.1016/j.cie.2015.04.027.

[9] Cong M, Qu L. (2015). Multiobjective optimization of switched reluctance motors based on design of experiments and particle swarm optimization. IEEE Transactions on Energy Conversion, 30 (3), pp. 1144-1153. https://doi.org/10.1109/tec.2015.2411677.

[10] Cheng S, Hao Z, Shu Z. (2016). An innovative hybrid multi-objective particle swarm optimization with or without constraints handling. Applied Soft Computing, 47, pp. 370-388.

https://doi.org/10.1016/j.asoc.2016.06.012.

[11] Zhang H, Yang Z. (2018). Accelerated particle swarm optimization to solve large-scale network plan optimization of resource-leveling with a fixed duration. Mathematical Problems in Engineering, pp. 1-11.

Masuda K, Kurihara K. (2015). A constrained global optimization method based on multiobjective particle swarm optimization. Electronics \& Communications in Japan, 95 (1), pp. 43-54. https://doi.org/10.1002/ecj.10385.

[12] Lin Q, Li J, Du Z, Chen J. (2015). A novel multiobjective particle swarm optimization with multiple search strategies. European Journal of Operational Research, 247 (3), pp. 732-744. https://doi.org/10.1016/j.ejor.2015.06.071.

[13] Cao B, Zhao J, Lv Z, Liu X, Yang S, Kang X, Kang K. (2017). Distributed Parallel Particle Swarm Optimization For Multi-Objective And ManyObjective Large-Scale Optimization. IEEE Access, PP (99), pp. 1-1. https://doi.org/10.1109/ACCESS.2017.2702561.

[14] Wood DA. (2017). Gas and oil project Time-costquality tradeoff: Integrated stochastic and fuzzy multi-objective optimization applied a memetic, nondominated, sorting algorithm. Journal of Natural Gas Science and Engineering, pp. S187551001730224X. https://doi.org/10.1016/j.jngse.2017.04.033.

[15] Xue Y, Chen WN, Gu T, Zhang H, Yuan H, Kwong S, Zhang J. (2017). Set-based discrete particle swarm optimization based on decomposition for permutation-based multiobjective combinatorial optimization problems. IEEE Transactions on Cybernetics, PP (99), pp. 1-15.

https://doi.org/10.1016/j.jngse.2017.04.033. 